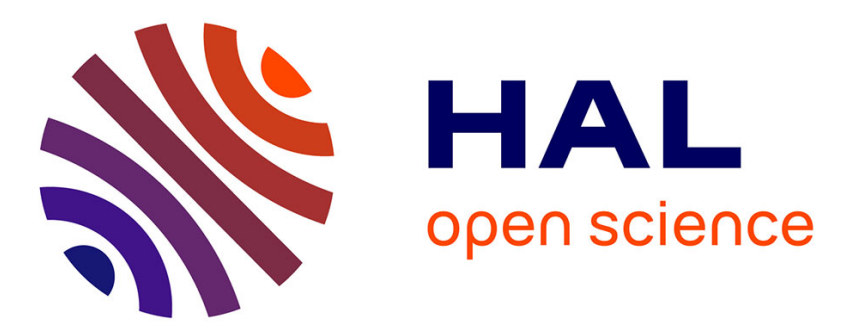

\title{
A New Branch of the Spectrum of Single Domain Wall Excitations in Magnetic Garnet Films
}

\author{
V. Synogach, H. Dötsch
}

\section{To cite this version:}

V. Synogach, H. Dötsch. A New Branch of the Spectrum of Single Domain Wall Excitations in Magnetic Garnet Films. Journal de Physique IV Proceedings, 1997, 07 (C1), pp.C1-451-C1-452. 10.1051/jp4:19971183 . jpa-00254832

\section{HAL Id: jpa-00254832 https://hal.science/jpa-00254832}

Submitted on 1 Jan 1997

HAL is a multi-disciplinary open access archive for the deposit and dissemination of scientific research documents, whether they are published or not. The documents may come from teaching and research institutions in France or abroad, or from public or private research centers.
L'archive ouverte pluridisciplinaire HAL, est destinée au dépôt et à la diffusion de documents scientifiques de niveau recherche, publiés ou non, émanant des établissements d'enseignement et de recherche français ou étrangers, des laboratoires publics ou privés. 


\title{
A New Branch of the Spectrum of Single Domain Wall Excitations in Magnetic Garnet Films
}

\author{
V.T. Synogach and H. Dötsch* \\ Institute for Solid State Physics, Russian Academy of Sciences, Chernogolovka, 142432 Moscow district, \\ Russia \\ * University of Osnabrück, 49069 Osnabrück, Germany
}

\begin{abstract}
B i$-substituted [110] and [100] oriented garnet films with in-plane magnetization are studied by means of planax excitation-detection structures at microwave frequencies. New multiple resonance modes of single domain walls with very low linewidth $(4.2 \mathrm{MHz})$ are observed at frequencies near $1 \mathrm{GHz}$. The resonances are excited by rf magnetic fields which are parallel or perpendicular to the wall plane. Resonance frequencies show a nonlinear dispersion dependence on the mode number. They decrease with an increasing static in-plane magnetic field normal to the wall plane. With decreasing film thickness the resonance frequencies increase. In addition the well known low-frequency resonances related to the wall translations or its flexural vibrations (Goldstone modes) are also observed in these samples.
\end{abstract}

\section{Introduction}

Epitaxial garnet films are currently investigated for a wide range of microwave and magnetooptical applications. Extremely low ferrimagnetic resonance linewidth and spin-wave damping of garnets allow to drive effectively different types of domain and domain wall excitations. Large Faraday rotation and low optical absorption of Bi-substituted garnet films are the basis to achieve high-frequency modulation and deflection of guided optical modes. In most cases these films have a large uniaxial anisotropy so that the magnetization is oriented normal to the film plane (so-called bubble films). In view of applications in integrated optics films with in-plane magnetization could also be very attractive. However, domain and domain wall dynamics in such films having low anisotropy constant $K_{u}$ and high saturation magnetization $M_{s}$ (i.e. $Q=K_{u} / \mu_{0} M_{s}^{2} \ll 1$ ) are not investigated as intensively as in bubble films. Here we present the results of an investigation of $B i$ - substituted yttrium and lutetium iron garnet films (Bi:YIG and $B i: L I G)$ grown by liquid-phase epitaxy on $[110]$ and $[100]$ oriented substrates of gadolinium gallium garnet.
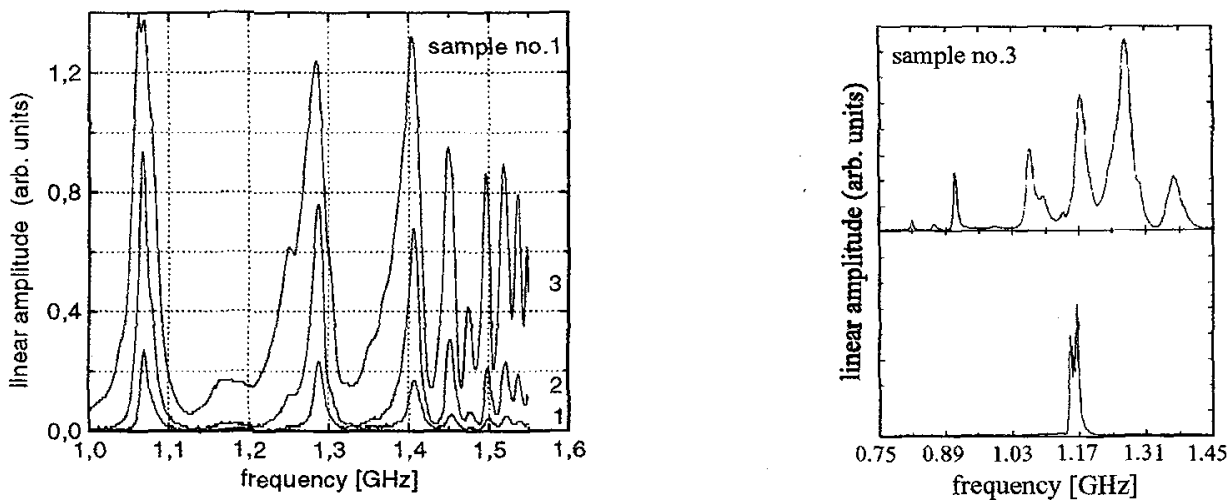

Figure 1: Frequency response of a single $180^{\circ}$ domain wall in [110] oriented $B i: Y I G$ film (left) and [100] oriented $B i: L I G$ film (right). The curves 1,2 and 3 at the left plot correspond to different input rf power levels $-35 \mathrm{dBm},-25 \mathrm{dBm}$ and $-15 \mathrm{dBm}$ respectively. The lower plot at the right figure corresponds to the FMR signal without domain wall in the excitation region. 

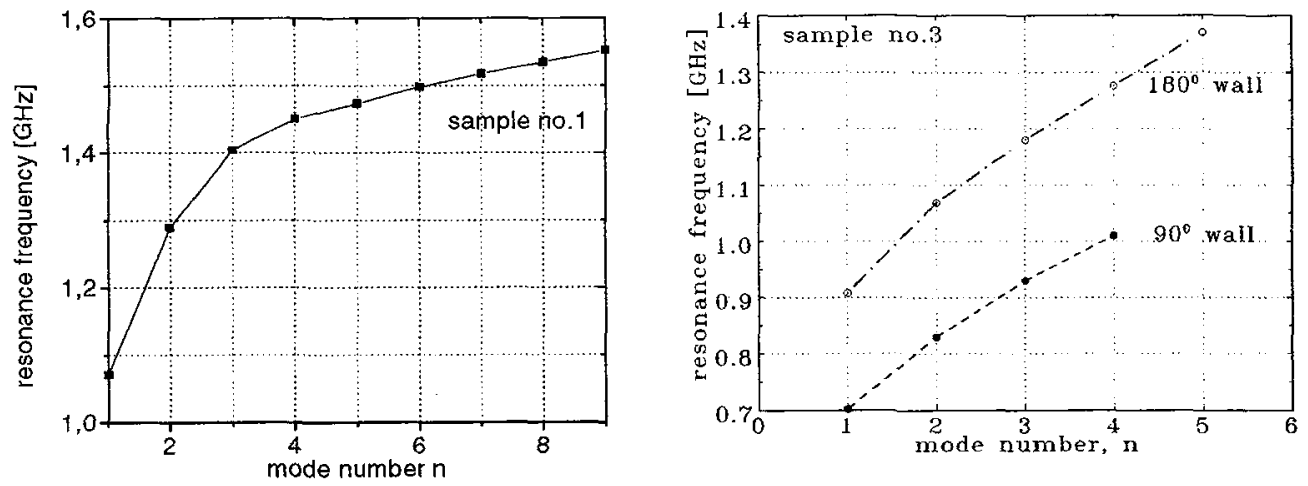

Figure 2: Plot of resonance frequency vs mode number $n$ for $180^{\circ}$ domain walls in [110]-oriented films (left) and $180^{\circ}$ and $90^{\circ}$ domain walls in $[100]$-oriented films (right).

\section{Results and discussion}

All the films studied have in-plane magnetization due to the proper choice of the parameters of cubic, uniaxial and orthorhombic anisotropy constants $K_{1}, K_{u}, K_{i}$, respectively. A planar excitation-detection structure - slot line and coplanar waveguide - is used to study the domain wall response to high-frequency magnetic fields [1]. The size of the structure is smaller than the domain size so that the excitation of a single domain wall can be measured.

The frequency dependence of the $180^{\circ}$ domain wall response displays a set of very sharp resonances both for [110] and $[100]$ oriented samples (figure 1). They have a nonlinear dipersion dependence of the frequency on the mode number (figure 2). The resonance frequencies decrease with increasing in-plane magnetic field normal to the wall plane. The resonance frequencies are the same when the exciting of magnetic field is parallel or perpendicular to the wall. A strong coupling between neighbouring walls is observed, if their distance becomes small. In this case each resonance is split into two coupled resonant modes.

In [100] oriented samples $180^{\circ}$ walls parallel to the [011] and [011] directions and $90^{\circ}$ walls parallel to the [010] and [001] directions are observed. The resonance frequencies of $90^{\circ}$ domain walls are found to be lower than those of $180^{\circ}$ walls (see right plot in figure 2). The character of the dispersion dependence for $90^{\circ}$ and $180^{\circ}$ walls is similar to that in $[110]$ oriented films.

The resonance frequencies increase with decreasing film thickness but do not depend on the geometric form of the sample. Therefore these resonances are due to the excitation of standing waves across the sample thickness. Furthemore, they are supposed to be related to the new branch of domain wall excitations predicted by Gilinskii [2]. It differs from the known mode of wall translations or its flexural vibrations (Goldstone mode). The latter kind of resonances is also observed in our samples at lower frequencies (in the range of $40-500 \mathrm{MHz}$ ) and has the linear dispersion. The small value of the frequency gap of this lower mode is due to the fact that in our samples restoring force which define the equilibrium wall position is very small.

In the Gilinskii mode both wall translations and oscillations of the magnetization transverse to the wall plane are involved. Thus, contrary to the Goldstone mode, the Gilinskii mode can be driven by rf fields both perpendicular and parallel to the wall plane as observed in our experiments. The frequency gap of the Gilinskii mode is proportional to the uniaxial anisotropy constant: $\omega_{G}=\gamma 2 K_{u} / M_{s}$ [2] ( $\gamma$ is the gyromagnetic ratio). This is in qualitative agreement with our observations that films with lower $K_{u}$ show lower resonance frequencies. Numerical simulations of the dispersion law $\omega(k)$ for the Gilinskij mode [3] show a nonlinear dispersion at large wave vectors $k$ and that $d^{2} \omega / d k^{2}<0$. This also agrees with the measured dependence of resonance frequency on the mode number (figure 2 ). Unfortunately, the theory $[2,3]$ was developed for the case of ferromagnets with a pure uniaxial anisotropy and can not be applied directly to the materials studied here, having in addition cubic and orthorhombic anisotropies.

\section{Acknowledgements}

V.T.S. thanks Alexander von Humboldt Stiftung for support and hospitality during his stay in Germany.

\section{References}

[1] B. Lührmann, H. Dötsch, S. Sure, Appl. Phys. A, 57, (1993) 553-559.

[2] I. A. Gilinskii, Zh. Eksp. Teor. Fiz. 68, (1975) 1032 [Sov. Phys. JETP, 41 (1975) 511 ].

[3] I.A. Shimokhin, phys. stat. sol (b) 167 (1991) 243-250. 